\title{
Structural alterations to the pulmonary circulation in fulminant hepatic failure
}

\author{
ADRIAN WILLIAMS, PETER TREWBY, ROGER WILLIAMS, \\ AND LYNNE REID
}

From the Department of Experimental Pathology, Cardiothoracic Institute, London SW3 6HP, and the Liver Unit, Kings College Hospital, London SE5, UK

ABSTRACT Like patients with chronic liver disease, those with coma due to fulminant hepatic failure may show arterial hypoxaemia even in the absence of pulmonary complications, and in both it is attributed to increased intrapulmonary arteriovenous admixture. This study is concerned with the structural alterations in the pulmonary circulation of patients who have died from fulminant hepatic failure. Precise quantitative morphometric techniques applied to the injected and inflated lung have shown the major abnormality to be a diffuse dilatation of the pulmonary vascular bed affecting arteries and veins of all structural types. At an intra-acinar level the diameter of arteries accompanying respiratory bronchioles was $232.97 \mu \mathrm{m}( \pm$ SD 46.35$)$ compared with $177 \cdot 76 \mu \mathrm{m}( \pm$ SD 30.43) in controls $(\mathrm{P}<0.01)$. In two-thirds of the patients pleural spider naevi were seen and, throughout the lung, similar significant dilatation of precapillary vessels; but in only one patient were precapillary anastomoses shown. While intrapulmonary venous admixture undoubtedly contributes to hypoxia in fulminant hepatic failure, its exact relation to the structural changes is not yet determined.

The occasional association of cyanosis and finger clubbing with disease of the liver has been recognised since the turn of the century (Fluckiger, 1884; Gilbert and Fournier, 1895) while the more frequent occurrence of arterial oxygen desaturation without cyanosis is a more recently established association (Snell, 1935). These observations have been concerned with chronic liver disease (CLD) but desaturation with hypoxia has also been reported in fulminant hepatic failure (FHF). Tyor and Sieker (1959) in a review of the "biochemical, blood gas, and peripheral circulatory alterations" in hepatic coma included three cases of FHF in which arterial oxygen desaturation was noted. More recently, with the increase in paracetamol self-poisoning and the development of liver failure units, hypoxia has become recognised as a frequent feature of this syndrome even in the absence of the clinical or radiological signs of pulmonary infection or oedema commonly found in severely ill and debilitated patients (Clark et al, 1973; Ward et al, 1977).

The mechanism responsible for the arterial oxygen desaturation in liver disease has been the subject of much debate, though it is now generally accepted that arteriovenous admixture is the main cause of desaturation and cyanosis in patients with cirrhosis (Bashour and Cochran, 1961) and, as recently shown, in those with FHF as well (Ward et al, 1977). Evidence for an intrapulmonary site for this admixture has been provided by postmortem injection studies of the pulmonary arterial tree, which have shown multiple small pulmonary arteriovenous fistulae in a few cases (Rydell and Hoffbauer, 1956; El Gamal et al, 1970). Berthelot et al (1966) examined the pulmonary circulation in 12 patients with hepatic cirrhosis by injecting the pulmonary arterial system with a barium/gelatin suspension. In all cases the fine peripheral branches of the pulmonary arterial tree were dilated and, in more than half, pleural spider naevi were seen, but precapillary anastomoses were found in only one case. They suggested that the dilated pleural vessels offer a pathway along which blood is shunted away from the alveolar respiratory surface directly to the pulmonary veins.

While arteriovenous admixture is well documented in CLD and a possible pathophysiological basis has been suggested, in FHF, although hypoxia is a recognised complication, the presence of 
arteriovenous admixture has only recently been confirmed and the pathological changes in the lung are unknown. The present study was undertaken to determine the structural changes in the pulmonary circulation in FHF, to correlate these changes with the clinical and physiological findings, and to compare the changes with those occurring in cirrhosis. Applying precise quantitative morphometric techniques to the injected and inflated lung, the size, number, wall structure, and distribution of the pulmonary arteries and veins have been established in the lungs of 12 patients who died of FHF.

\section{Methods}

We studied the lungs from 12 patients who died with hepatic encephalopathy due to FHF. One lung was obtained from each of eight patients and both lungs from the remaining four. The clinical details are summarised (table). Details of the clinical management have been described elsewhere (Ward et al, 1977). The duration of coma varied from three to 23 days and the length of the illness preceding this coma from one to 42 days. The $\mathrm{PO}_{2}$ was determined in all but one case, and in 10 patients the degree of a-v admixture was assessed by the method of Berggren (1942). Here the concentration of inspired oxygen was increased to $100 \%$ for 20 minutes using a close-fitting face mask in those cases not already being ventilated. Blood was taken into cooled syringes from pulmonary and systemic arterial lines, the amount of admixture calculated in the usual way (Berggren, 1942) and expressed as a percentage of cardiac output. Mixed venous $\mathrm{PCO}_{2}$ was measured directly. These recordings were made during a stable period

Clinical details

\begin{tabular}{ccllllll}
\hline $\begin{array}{l}\text { Case } \\
\text { No }\end{array}$ & Age & Diagnosis & $\begin{array}{l}\text { Illness } \\
\text { (days) } \\
\text { preceding } \\
\text { coma }\end{array}$ & $\begin{array}{l}\text { Duration } \\
\text { (days) } \\
\text { of coma }\end{array}$ & $\begin{array}{l}\text { Mean } \\
\text { shunt } \\
\% \text { cardiac } \\
\text { output }\end{array}$ & $\begin{array}{c}\text { X-ray } \\
\text { "oedema" }\end{array}$ \\
\hline 1 & 28 & Paracetamol & 1 & 3 & 39 & ++ \\
2 & 15 & Paracetamol & 2 & 3 & $29 \cdot 6$ & + \\
3 & 31 & Paracetamol & 4 & 3 & $31 \cdot 7$ & - \\
4 & 35 & Halothane & 8 & 3 & & - \\
5 & 28 & Hepatitis A & 18 & 3 & $28 \cdot 6$ & - \\
6 & 19 & Paracetamol & 3 & 4 & $26 \cdot 3$ & ++ \\
7 & 26 & Paracetamol & 3 & 4 & 16 & - \\
8 & 18 & Paracetamol & 3 & 4 & 36 & - \\
9 & 43 & Hepatitis A & 10 & 8 & $37 \cdot 5$ & - \\
10 & 23 & Hepatitis A & 5 & 12 & $27 \cdot 3$ & + \\
11 & 49 & Hepatitis A & 42 & 12 & 22 & ++ \\
$12 *$ & 16 & Paracetamol & 3 & 23 & - & - \\
\hline
\end{tabular}

* Man-all others women.

+Loss of vessel definition.

++ Pulmonary shadows. of coma before the onset of terminal complications. Significant admixture was found in all cases examined, and ranged from 16 to $29 \%$ of the cardiac output. In a group of normal volunteers similar studies showed the mean value of admixture to be less than $5 \%$.

Representative chest radiographs were examined. In all, the radiographs were taken within 24 hours of the shunt being measured. Five showed evidence of mild pulmonary oedema, as judged in two by loss of vessel definition and in the other three by the presence of a pulmonary infiltrate; the remaining seven were normal.

For controls two lungs were obtained from each of four people (three men aged respectively 26 , 40 , and 70 , and one woman aged 26 years) who died without liver or lung disease, the cause of death being in each case a cerebrovascular accident.

The methods used in the preparation and morphological analysis of the lungs have been described in detail elsewhere (Davies and Reid, 1970). The pulmonary arterial or venous system was injected with a Micropaque/gelatin suspension at $60^{\circ} \mathrm{C}$ and at a pressure of $100 \mathrm{~cm}$ of water. The arterial circulation was injected in all 12 cases of FHF and, in addition, the venous circulation in four. In all four controls both systems were injected. Since this injection technique distends and fills all vessels greater than $15 \mu \mathrm{m}$ in diameter but does not cross the capillary bed, reflux from the pulmonary veins after arterial injection is evidence of the presence of precapillary arteriovenous anastomoses. The lungs were inflated through the trachea with $10 \%$ formol saline at a pressure of $45 \mathrm{~cm}$ of water until the pleura was tense. The pleural surface was examined for the presence of injection material in blood vessels.

Ten blocks of tissue were then taken from each lung using a stratified random sampling technique (Dunnill, 1962). These were routinely processed, embedded in paraffin, and standard $4 \mu \mathrm{m}$ sections were cut and stained with Verhoeff's elastic van Gieson. On these the following quantitative microscopic analysis was made.

Size of arteries with airways-Peripheral arteries can be landmarked by identifying microscopically the accompanying airway, that is, terminal or respiratory bronchiole, alveolar duct, or alveolar sac. Corresponding vessels can therefore be identified in different cases and compared. Measurements were made of the external diameter of arteries accompanying respiratory bronchioles (2050 arteries/case) and alveolar ducts (about 50 arteries/case) using a calibrated eyepiece graticule. 
Since veins do not accompany airways but run at the periphery of the lobule, it is not possible to landmark them in this way.

Medial wall thickness-Vessel wall thickness was measured from internal to external elastic lamina and related to external diameter. In the normal lung the percentage medial wall thickness $(2 \times$ wall thickness $\times 100 /$ external diameter $)$ is related to external diameter, being greater in the smallest vessels and decreasing with increasing diameter until, in arteries and veins of more than $300 \mu \mathrm{m}$ in diameter, it remains fairly constant.

Population counts-Arteries or veins below $250 \mu \mathrm{m}$ in diameter are structurally a mixed population. Along any arterial pathway the complete muscle coat gives way to a spiral of muscle before the vessel becomes non-muscular. This occurs at a diameter larger than a capillary. In a given area of a microscopic section all arteries below $300 \mu \mathrm{m}$ in diameter are examined and their structure noted, whether muscular, partially muscular, or nonmuscular. The proportion of each structural type within a given size range is then calculated. Extension of muscle to the periphery is shown by a shift to the left while dilatation is shown by a shift to the right.

$V$ essel number-The number of arteries or veins per unit area of lung section was calculated from the number of filled vessels greater than $25 \mu \mathrm{m}$ in an average of 50 microscopic fields using a lowpower objective, a unit area being taken as a microscopic field. In the same area the number of vessels was related to the number of alveoli to minimise any difference caused by differences in the degree of inflation of individual lungs.

A post-mortem lung biopsy was performed soon after death in seven patients to provide material for ultrastructural studies. Tissue was fixed for one to four hours in $2 \%$ glutaraldehyde in cacodylate buffer and then overnight in cacodylate buffer. After post-fixation in $1 \%$ osmium tetroxide it was dehydrated and embedded in Araldite. One $\mu \mathrm{m}$ sections were cut, stained with Toluidine blue in $1 \%$ borax, and studied by light microscopy. The statistical significance of the difference in measurements between subjects with FHF and the controls was examined using Student's $t$ test.

\section{Results}

\section{MACROSCOPIC APPEARANCE}

In eight of the 12 arterial injections numerous short, spidery pleural vessels were filled, their fine branches reminiscent of the cutaneous spider naevus (fig 1). The number of such spiders varied. In some cases they were sufficiently numerous to cover completely an area of pleura while in others they were fewer so that individual spiders could be easily identified and counted, but their presence contrasts strongly with the normal pleura in which no vessels fill.

In one case (No 3 ) reflux of injection material occurred from veins.

\section{MICROSCOPIC APPEARANCE}

The lung architecture was intact in all cases. Figure $2 \mathrm{a}$ is a photomicrograph of the normal injected and inflated lung and fig $2 b$ of a case of FHF illustrating the diffuse dilatation of intraacinar arteries, which was confirmed by the following quantitative studies.

Size of arteries with airways (fig 3)-In control lungs the mean external diameter of arteries accompanying respiratory bronchioles was $177.76 \mu \mathrm{m}$ ( \pm SD 18.24). In FHF it was $232.97 \mu \mathrm{m}$ ( \pm SD $46 \cdot 35)$ a statistically significant difference $(P<0.01)$. Similarly, for arteries accompanying alveolar ducts the mean external diameter in FHF of $122.69 \mu \mathrm{m}$ $( \pm 19.65)$ was significantly greater $(P<0.01)$ than that of the controls, $88.1 \mu \mathrm{m}( \pm 17.59)$. The highest values were found in those cases with pleural spider naevi.

Percentage medial wall thickness (\%WT)-The mean \%WT of arteries and veins of all sizes in patients with FHF was less than normal, though the difference was not statistically significant. No significant difference was found between those cases with pleural spider naevi and those without. This thinning of the vessel wall is probably an effect of dilatation.

Population counts (fig 4)-It seems that dilatation affects arteries of all structural types as shown by a shift in the population curve to the right. This shift is produced by an increase in size of the largest non-muscular, the largest partially muscular, and the smallest muscular arteries. A similar shift in the venous population count was found. The mean diameter of the smallest muscular vein was $157.5 \mu \mathrm{m}( \pm \mathrm{SD} 7.5)$ compared with a control value of $80 \mu \mathrm{m}( \pm 20)(\mathrm{P}<0.05)$. Similarly, the largest non-muscular vein was $287 \mu \mathrm{m}( \pm 27.5)$ compared with $180 \mu \mathrm{m}( \pm 5)$ in the controls $(\mathbf{P}<0.05)$.

Vessel number-For the four controls the mean number of arteries per unit area was 8.9 ( \pm SD $1 \cdot 1)$ and for the 12 cases of FHF $9.9( \pm 3.03)$. The difference is not statistically significant.

The number of veins per unit area was also normal. 


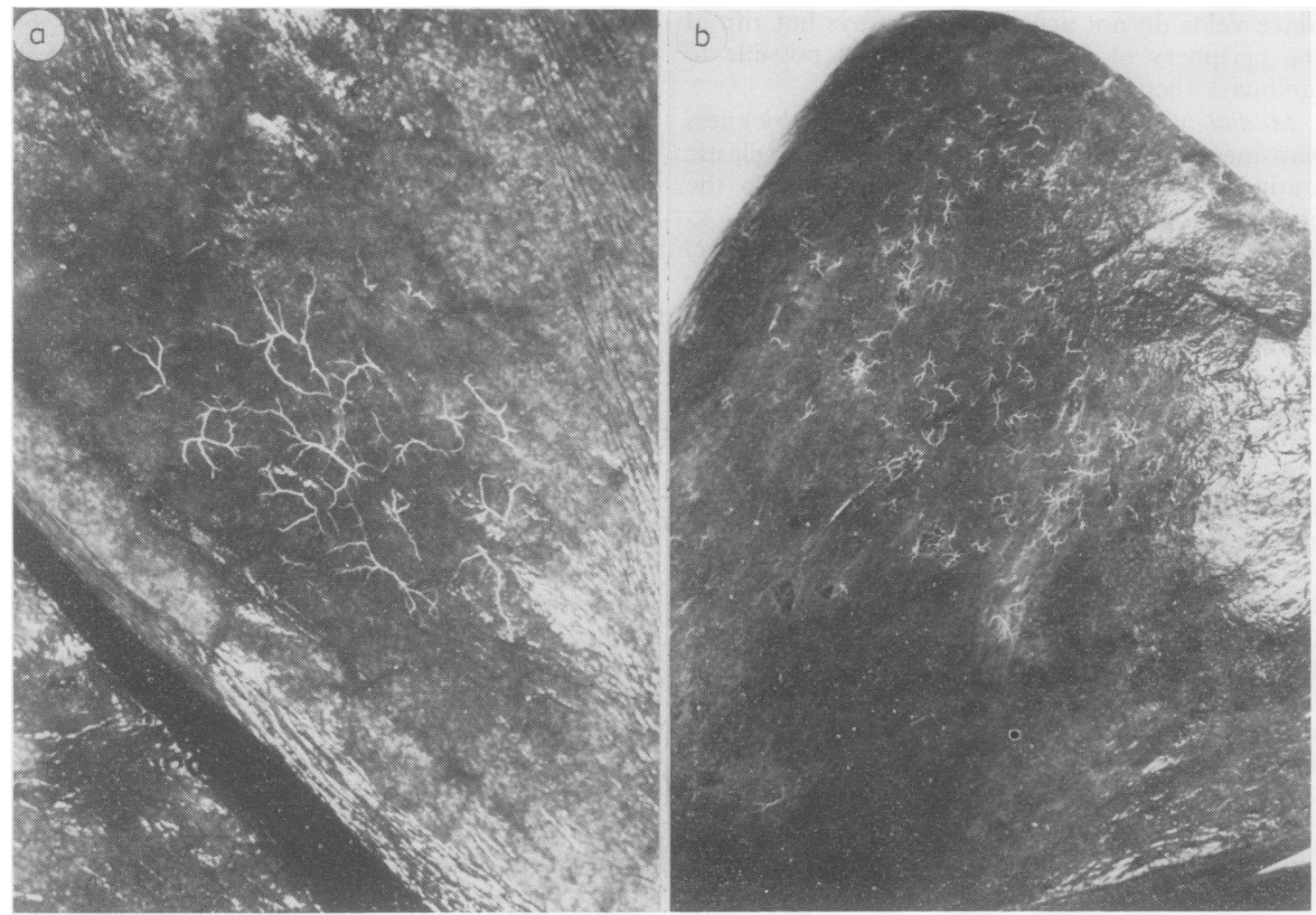

Fig 1 Macroscopic appearance of the pleura showing dilated pleural vessels, single (a) or multiple (b). Part of the pleura appears normal in that it is vessel free.

\section{PRECAPILlaRIES}

Alveolar wall structure is seen in more detail in $1 \mu \mathrm{m}$ Toluidine sections (fig 5). In four of the seven biopsies an increase in lumen size of alveolar wall vessels was apparent. These vessels are not filled by the injection technique and are therefore not included in the counts described above. Undistended, the vessels are about $10-15 \mu \mathrm{m}$ in diameter and can be considered precapillaries.

\section{Discussion}

These studies of the changes in acute liver failure have shown for the first time that significant structural changes develop in the pulmonary circulation in this condition and that they can occur rapidly. The essential nature of the structural abnormality is diffuse dilatation affecting all intraacinar vessels. In the pleura, spider naevi are evidence of the severity of the dilatation, although even when they are not present diffuse dilatation of small subpleural vessels is found. These changes are similar to those seen in cirrhosis of the liver, although generally not as severe. The certain recognition and analysis of these changes were made possible by the method of injection applied to the pulmonary circulation and by subsequent radiographic and quantitative morphometric analysis. The preponderance of women can be ignored since the response of the lung to aging or to disease has been shown previously to be the same for either sex (Hislop and Reid, 1973). The $1 \mu \mathrm{m}$ sections prepared from separate blocks of tissue, although uninjected, showed that vessels beyond the range of our injection were affected. This change is seen both on the arterial and venous side of the capillaries.

It is known that under the conditions used the injection medium fills vessels down to $15 \mu \mathrm{m}$ in diameter but does not cross the capillary bed (Davies and Reid, 1970). In the one case in this series in which reflux occurred this was within seconds of the start of the arterial injection, suggesting the presence of either a few major precapillary arteriovenous communications or numerous small ones. Since no major shunts were 


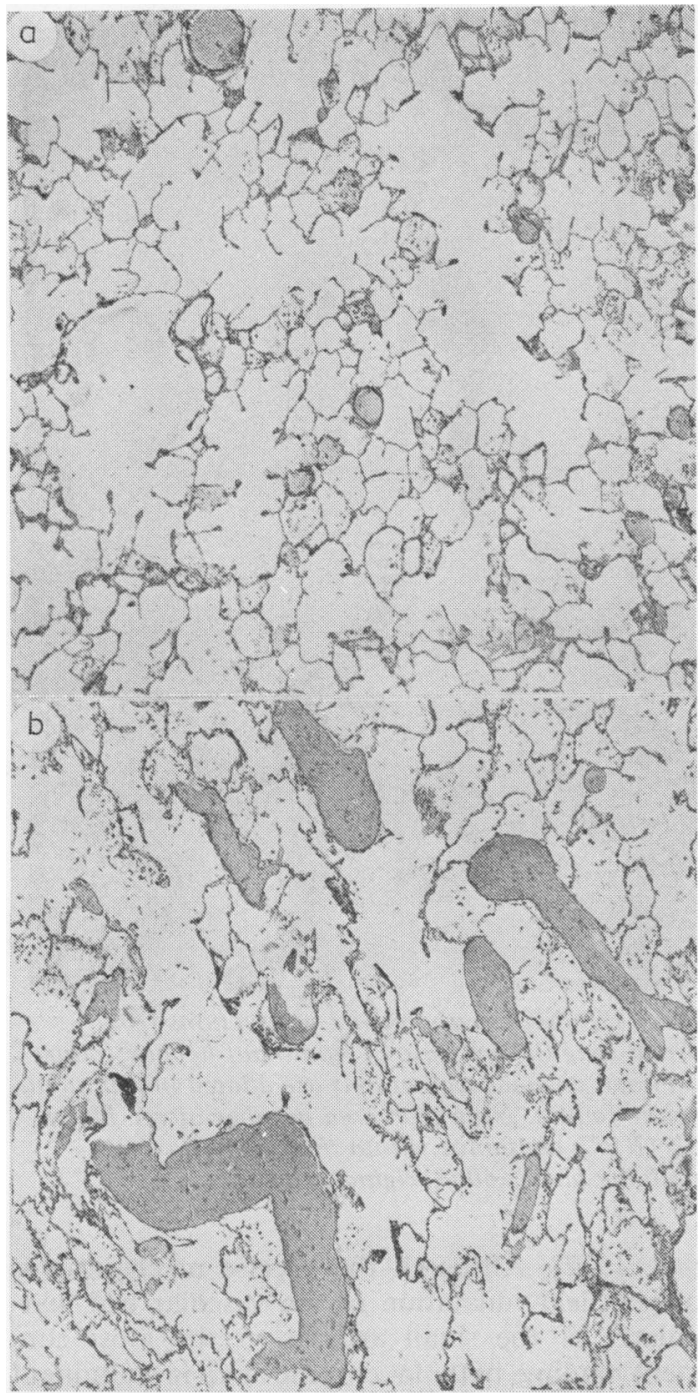

Fig 2 Photomicrograph of a normal lung (a) and lung from patient with fulminant hepatic failure (b) showing dilated intra-acinar arteries. Elastic van Gieson stain $\times 48$ (original magnification).

seen this reflex probably represents a more severe degree of the diffuse dilatation. It is the diffuse dilatation, so frequent a feature of liver disease, that is of special significance functionally. The injection methods probably underestimate the degree of diffuse dilatation that occurs in life. In the normal circulation two-to-three-fold dilatation of capillaries and small vessels has occurred (Glazier et al, 1969). If in liver disease this is superimposed on a circulation already abnormally

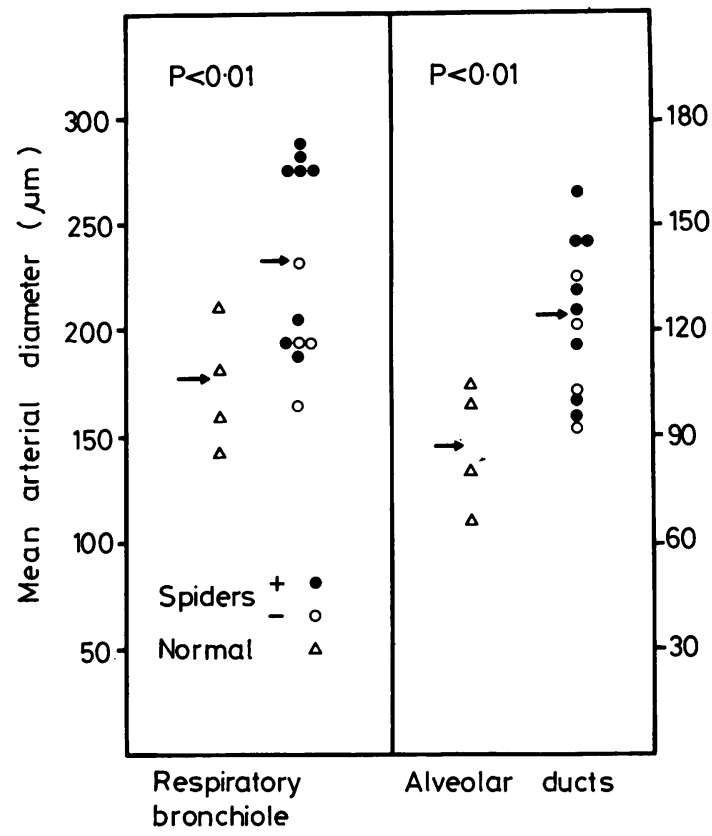

Fig 3 Diagram indicating size of arteries accompanying respiratory bronchioles and alveolar ducts in fulminant hepatic failure and in normal lungs. Mean diameter of arteries in fulminant hepatic failure is significantly greater than corresponding arteries in the normal.

dilated, the functional significance with respect to "shunt" of the dilatation we have shown will be even greater.

Lung scanning techniques support the functional importance of the acute dilatation in cirrhosis of the liver. Stanley and Woodgate (1972) reported abnormal passage of intravenously injected albumin macroaggregates (average diameter exceeding $20 \mu \mathrm{m})$ across the pulmonary vascular bed. Recently in four patients with advanced liver disease the fate of intravenous injection of radioactive particles $20-80 \mu \mathrm{m}$ in diameter has been followed by whole body scanning. In all, extrapulmonary deposition occurred, the fraction escaping the pulmonary capillary net being a measure of the "shunt" (Wolfe et al, 1977).

The pathogenesis of the dilatation is not known. Abnormalities of the systemic circulation have long been recognised as a feature of liver diseasesuch as cutaneous spider naevi and a raised cardiac output (Bean, 1959). The mechanism for dilatation in the pulmonary circulation may be similar to those that operate in the systemic. In patients with liver cirrhosis Daoud et al (1972) found that the 


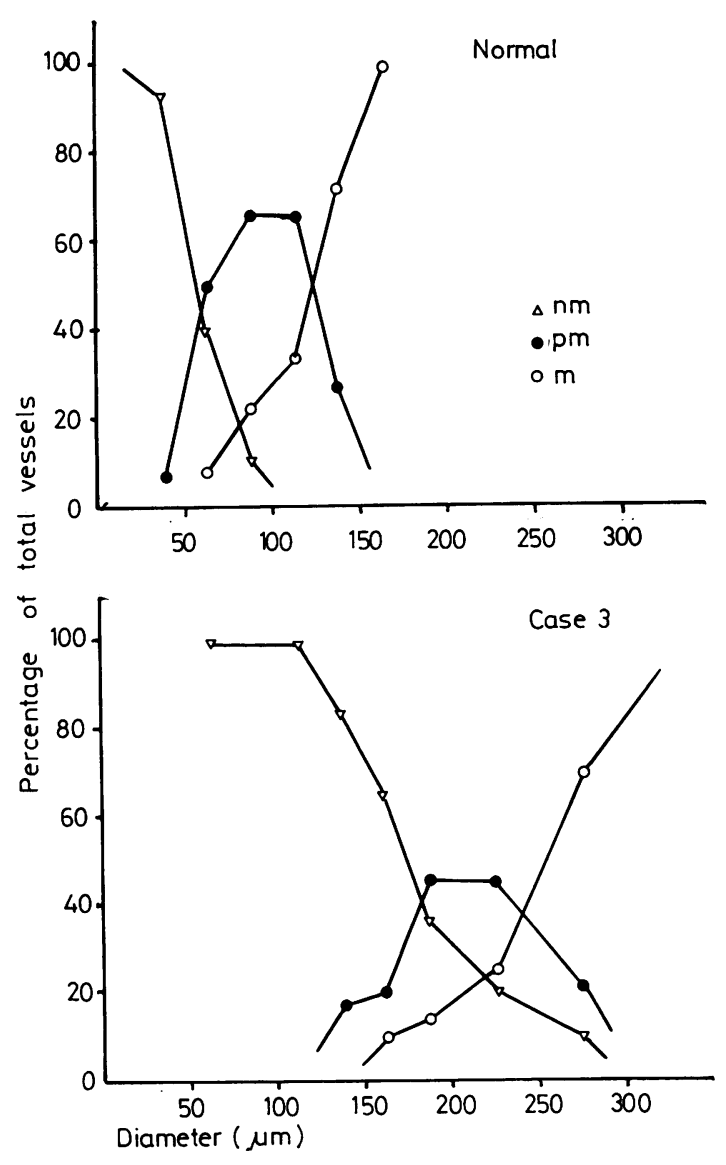

Fig 4 Distribution of arterial types in case of fulminant hepatic failure and normal lung showing shift to right due to dilatation.

pulmonary circulation fails to respond to hypoxia by vasoconstriction.

Although the degree of venous admixture does not correlate with the degree of vascular dilatation assessed under conditions of maximum distension, absence of other pathological changes that would explain such large shunts suggest that the dilatation is functionally important. Arterial dilatation could contribute to desaturation in several ways. In three patients with portocaval shunts Cotes reported reduced pulmonary diffusing capacity for co (Cotes et al, 1968). He speculated that dilatation of alveolar vessels by increasing relative perfusion to the dependent parts of the lung decreased the effective surface available for gas exchange and so reduced the Duco. Other instances of a reduced DLCo in CLD have been reported (Stanley and Woodgate, 1971; Schomerus et al, 1975; Wolfe

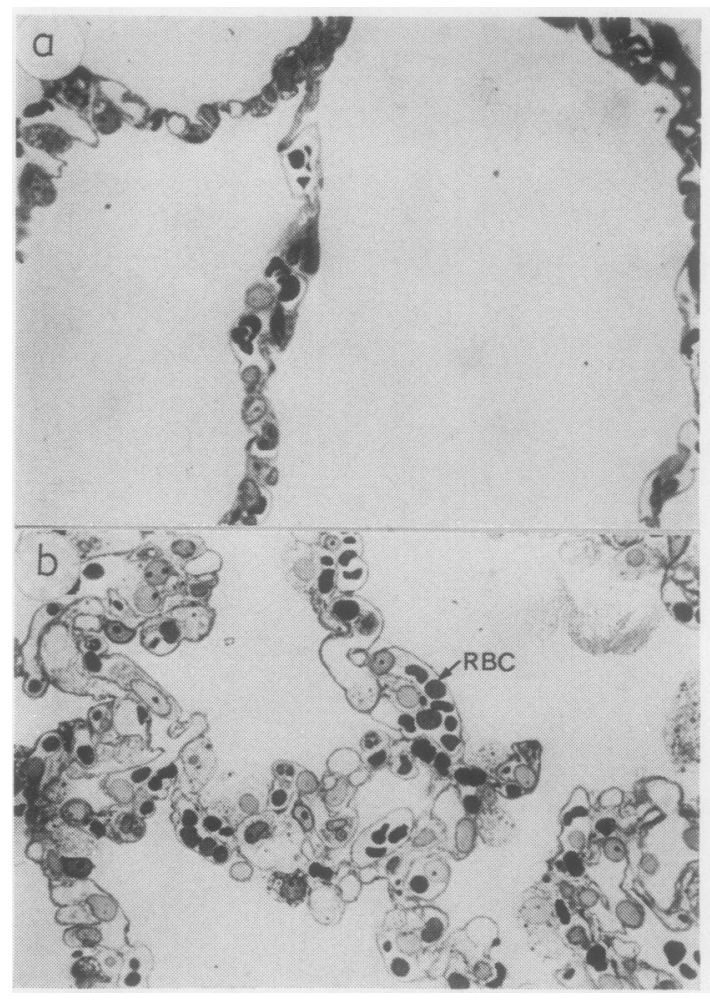

Fig 5 Photomicrographs of $1 \mu \mathrm{m}$ sections from normal lung (a) and case of fulminant hepatic failure (b). Small alveolar wall vessels are dilated in fulminant hepatic failure. Note increased number of red blood cells $(R B C)$ contained within these vessels.

Toluidine blue $\times 600$ (original magnification).

et al, 1977). Although the precise mechanism is not yet clear, dilatation of the vascular bed, particularly of the small arteries, is the most consistent finding both in chronic and in fulminant $\frac{}{5}$ liver disease: in some way blood is diverted from $\frac{7}{O}$ the region of gas exchange, although precapillary anatomic shunts are rare. In fulminant liver failure $\mathcal{N}^{\circ}$ as in chronic liver disease blood may be diverted $N$ through the pleural vessels: or the diffuse mild 0 dilatation of intra-alveolar wall arteries and capil- $\omega$ laries may suffice to produce a functional shunt.

\section{References}

Bashour, F A, and Cochran, P (1961). Alveolar- $\frac{T}{0}$ arterial oxygen tension gradients in cirrhosis of the $\stackrel{\vec{D}}{\vec{D}}$ liver. Further evidence of existing pulmonary arteriovenous shunting. American Heart Journal, $\underset{\mathbb{Q}}{\mathbb{Q}}$ 71, 734-740.

Bean, W B (1959). Vascular Spiders and Related Lesions of the Skin, p 388. Blackwell, Oxford. 
Berggren, S M (1942). The oxygen deficit of arterial blood caused by non-ventilating parts of the lung. Acta Physiologica Scandinavica, 4, suppl no 11.

Berthelot, P, Walker, J G, Sherlock, S, and Reid, L (1966). Arterial changes in the lungs in cirrhosis of the liver-lung spider nevi. New England Journal of Medicine, 274, 291-298.

Clark, R, Thompson, R P H, Borirakchanyavat, V, Widdop, B, Davidson, A R, Gouldings, R, and Williams, R (1973). Hepatic damage and death from overdosage of paracetamol. Lancet, 1, 66-68.

Cotes, J E, Field, G B, Brown, G J A, and Read, A E (1968). Impairment of lung function after portocaval anastomosis. Lancet, 1, 952-955.

Daoud, F S, Reeves, J J, and Schaefer, J W (1972). Failure of hypoxic vasoconstriction in patients with liver cirrhosis. Journal of Clinical Investigation, 51, 1076-1080.

Davies, G, and Reid, L (1970). Growth of the alveoli and pulmonary arteries in childhood. Thorax, 25, 669-681.

Dunnill, M S (1962). Quantitative methods in the study of pulmonary pathology. Thorax, 17, 320-328.

El Gamal, M, Stoker, J B, Spiers, E H, and Whitaker, W (1970). Cyanosis complicating hepatic cirrhosisa report of a case due to multiple arteriovenous fistulas. American Journal of Cardiology, 25, 490 494.

Flückiger, M (1844). Vorkommen von trommelschlägelförmigen Fingerendphalanen ohne chronische Veränderungen an den Lungen oder am Herzen. Wiener Medizinische Wochenschrift, 34, 1457-1458.

Gilbert, A, and Fournier, L (1895). La cirrhose hypertrophique avec ictère chez les enfants. Comptes Rendu des Séances de la Société de Biologie, 10, 2nd series, 419.

Glazier, J B, Hughes, J B M, Maloney, J E, and West, J B (1969). Measurement of capillary dimensions and blood volume in rapidly frozen lungs. Journal of Applied Physiology, 26, 65-71.
Hislop, A, and Reid, L (1973). Fetal and childhood development of the intrapulmonary veins in man: branching pattern and structure. Thorax, 28, 313319.

Rydell, R, and Hoffbauer, P W (1956). Multiple pulmonary arteriovenous fistulas in juvenile cirrhosis. American Journal of Medicine, 21, 450-460.

Schomerus, H, Buchta, I, and Arndt, H (1975). Pulmonary function studies and oxygen transfer in patients with liver cirrhosis and different degrees of portasystemic encephalopathy. Respiration, 32, $1-6$.

Snell, A M (1935). Effects of chronic disease of the liver on composition and physiochemical properties of blood: change in serum proteins, reduction in the oxygen saturation of the arterial blood. Annals of Internal Medicine, 9, 690-711.

Stanley, N N, and Woodgate, D J (1971). The circulation, the lung, and finger clubbing in hepatic cirrhosis. British Heart Journal, 33, 469-472.

Stanley, N N, and Woodgate, D J (1972). Mottled chest radiograph and gas transfer defect in chronic liver disease. Thorax, 37, 315-323.

Tyor, M P, and Sieker, H O (1959). Biochemical, blood gas and peripheral circulatory alterations in hepatic coma. American Journal of Medicine, 27, 50-59.

Ward, M E, Trewby, P N, Williams, R, Strumin, L (1977). Acute liver failure-experience in a special unit. Anaesthesia, 32, 228-239.

Wolfe, J D, Tashkin, D P, Holly, F E, Brachman, M B, and Genovesi, M G (1977). Hypoxemia of cirrhosis. Detection of abnormal small pulmonary vascular channels by a quantitative radionuclide method. American Journal of Medicine, 63, 746753.

Requests for reprints to: Dr Lynne Reid, Department of Pathology, Children's Hospital Medical Center, 300 Longwood Ave, Boston, MA 02115, USA. 